\title{
Medición multidimensional de la pobreza: una propuesta exploratoria para Costa Rica
}

\author{
Mario Artavia \\ Univesidad de Chile
}

\section{Resumen}

Este estudio de caso se desarrolló con el objetivo general de elaborar una propuesta exploratoria para la medición multidimensional de la pobreza, contribuyendo con ello a la reflexión de la sociedad entorno a la definición de mecanismos que permitan superar la pobreza. Con este objetivo, se revisaron las metodologías de medición multidimensional de la pobreza que han sido adoptadas en América Latina. Posteriormente, a partir de la metodología de medición multidimensional desarrollada por Alkire y Foster, se calculó la incidencia de la pobreza para distintas líneas de corte entre dimensiones, evidenciándose una alta sensibilidad de los resultados a distintos valores del parámetro k. Utilizando un valor promedio $(\mathrm{k}=3)$ se identificó que el 2013 en Costa Rica un 31.5\% de la población sufre pobreza multidimensional. Las dimensiones asociadas a las tecnologías de la información, educación básica y calidad del empleo son las que identifican a la mayor cantidad de personas en situación de pobreza multidimensional, con ello se evidencia que las políticas sectoriales en dichos ámbitos han sido insuficientes para lograr los umbrales mínimos de bienestar establecidos en la medición

Palabras clave: Medición multidimensional de la pobreza, superación de la pobreza, bienestar.

\section{Multidimensional Measurement of Poverty: An Exploratory Proposal for Costa Rica}

\begin{abstract}
This case study was developed with the general objective to develope an exploratory proposal for multidimensional poverty measurement, contributing to the debate on the definition of mechanisms to poverty overcome. The methodologies of multidimensional poverty measurement that have been adopted in Latin America were reviewed. With Alkire and Foster's multidimensional measurement methodology, the incidence of poverty for different cut lines among dimensions was calculated, wich provided evidence of high sensitivity of the results to different values of the parameter $\mathrm{k}$. Using an average value $(\mathrm{k}=3)$ was identified that in Costa Rica in $2013,31.5 \%$ of the population suffers multidimensional poverty. The dimensions associated with information technology, basic education and job quality were those that identify as many people in multidimensional poverty, thereby evidenced that sectoral policies in these areas had been insufficient to achieve the minimum thresholds of well-being established in the measurement
\end{abstract}

Keywords: Multidimensionality measurement of poverty, overcoming poverty, well-being. 


\section{Introducción}

Luego de la celebración de la Cumbre del Milenio (2000), Costa Rica adopta frente a la comunidad internacional los Objetivos de Desarrollo del Milenio (ODM). Esta iniciativa busca determinar los desafíos urgentes que enfrentan los diferentes pueblos del planeta, siendo uno de los objetivos fundamentales la superación de la pobreza. Con respecto a esta materia, Costa Rica presenta un retraso importante ya que el Estado y la sociedad en general no han sido capaces de generar las condiciones que le permitan a un número importante de personas mejorar sus condiciones de vida, evidenciándose más bien un aumento en la vulnerabilidad y un deterioro en indicadores que son esenciales para garantizar un piso mínimo de bienestar.

El informe "Proyecto Bicentenario: objetivos, metas e indicadores de desarrollo para la Costa Rica del 2021" (2012) reconoce que el país ha realizado una fuerte inversión social, lo que le ha permitido alcanzar indicadores sociales que se ubican a la par de los que ostentan los países desarrollados. Sin embargo, persisten problemas de desigualdad y pobreza, lo que le impide al Estado "garantizar oportunidades de desarrollo y bienestar a la población en condiciones de equidad e igualdad" (MIDEPLAN, 2012: 31). Del mismo modo, el de la Nación (2014) señaló recientemente la existencia de un severo desgaste en los fundamentos del modelo de desarrollo seguido por el país desde los años 1990, lo que plantea la necesidad de reformular muchas de las apuestas de progreso en las que el Estado ha centrado buena parte de sus esfuerzos.

Al no existir una definición transversal de lo que es el desarrollo, este tiende a asimilarse únicamente a la noción de desarrollo económico, siendo el PIB y el PIB per cápita los indicadores más utilizados para medirlo. Esta visión economicista del desarrollo podría ocasionar que el crecimiento se convierta en el principal determinante de la pobreza, comprometiendo las políticas sociales hacia el aumento del ingreso monetario, sin considerar el fenómeno de la pobreza en todas sus dimensiones (Sanhueza, $2012)^{1}$.

Es fundamental un replanteamiento de la noción unidimensional de la pobreza, a fin de que esta pueda ser entendida como un fenómeno en el que intervienen una gran cantidad de elementos. De es-

\footnotetext{
${ }^{1}$ Un ejemplo de esto es la llamada "teoría del desborde" o trickle down effect, la cual plantea que los beneficios económicos prestados a las empresas y a los niveles de ingreso más elevados beneficiarían a la economía en su conjunto, permitiendo que los miembros más pobres de la sociedad se beneficien -por "desborde" o "goteo"- del aumento en la riqueza.
}

ta manera se puede avanzar hacia una concepción del desarrollo "como un proceso de expansión de libertades" (PNUD, 2013: 24) y no sólo como la acumulación de recursos.

El Estado costarricense, si bien reconoce que la pobreza no es homogénea, no cuenta al día de hoy con un instrumento oficial que dé cuenta de las múltiples dimensiones asociadas a dicho fenómeno. Las actuales mediciones están ligadas únicamente a indicadores monetarios (ingreso o consumo), es decir una mirada incompleta de un fenómeno complejo, perjudicando así la toma de decisiones.

Se plantea, de esta manera, la pregunta de investigación: ¿Cuáles son los principales desarrollos conceptuales y metodológicos que permitirían la elaboración de una propuesta para la medición multidimensional de la pobreza en Costa Rica?.

De esta manera, el objetivo de esta investigación es elaborar una propuesta exploratoria para la medición multidimensional de la pobreza en Costa Rica.

\section{Bienestar}

El bienestar es un concepto complejo que se ha intentado definir desde muchas disciplinas, generando un debate en torno a los mecanismos más apropiados para medirlo. Villatoro (2012) señala que en el ámbito académico y de diseño de políticas, la discusión sobre el bienestar y las formas de medirlo han estado dominadas "por las perspectivas filosóficas y económicas" (CEPAL, 2013: 9), siendo cada vez más común la incorporación de elementos subjetivos así como de aspectos materiales que van más allá del ingreso.

\section{La economía del bienestar: nociones genera- les}

La economía del bienestar hace referencia a una asignación de recursos socialmente óptima, tanto desde un punto de vista positivo como uno normativo. Esto se puede realizar desde diversos enfoques como el utilitarista, el contractual, y el enfoque de capacidades y funcionamientos.

El enfoque utilitarista entiende la utilidad como una aspiración natural del ser humano, quien no sólo la busca, sino que desea su maximización. Se considera que este es un concepto cardinal -una expresión cuantitativa y numérica-, por lo tanto se puede comparar interpersonalmente, ser monitoreado en el tiempo y establecer aproximativamente el valor máximo de utilidad en un determinado mo- 
mento. El bienestar social se construye a partir de la agregación de la satisfacción de las preferencias individuales, lo que implica que al maximizar la sumatoria de las utilidades personales se obtiene el bienestar general máximo (Bentham, 2014). Por su parte, Pigou (1920) propone desarrollar una medida monetaria del bienestar a partir de una unidad común (dinero) con la intención de establecer comparaciones entre individuos y sociedades.

La crítica a este enfoque dio origen al utilitarismo neoclásico, quienes rechazan la posibilidad de realizar comparaciones de orden cardinal, lo que implica que lo único que se puede señalar sobre el bienestar de una persona es que es superior (inferior) al de otra, sin poder asignarle una magnitud específica a dicha diferencia. Otros aportes importantes son la noción de asignación eficiente de los recursos (Pareto, 1909) y el reconocimiento de que el aumento del bienestar de un individuo puede generarse a costa del bienestar de otro, siempre y cuando opere algún tipo de medida compensatoria (Kaldor, 1939).

La teoría neoclásica del bienestar se ve limitada en su desarrollo luego de que Arrow (1951) postulara que en un mundo ordinal es imposible establecer ordenamientos sociales que sean compatibles con las diferencias individuales, siendo esto conocido como el teorema de la imposibilidad.

El enfoque contractual propone una teoría de la elección a partir de lo que la sociedad considera justo. Esto implica la existencia de un acuerdo social (contrato inicial) por medio del cual se establecen las preferencias ya no de un sólo individuo, sino de la sociedad en su conjunto. Esto permite construir una función de bienestar social en la que se mejore la posición de los individuos que están en peores condiciones (maximizar los mínimos). La propuesta parte del supuesto de que la estructura básica de las sociedad distribuye de manera igualitaria ciertos bienes primarios, definiendo estos como las "cosas que se presume que todo ser racional desea" (Rawls, 2006: 69) y tienen un uso en función del particular plan vida de cada persona. Estos bienes, según lo señalado por Rawls, van más allá del ingreso y la riqueza, incluyendo derechos, libertades, oportunidades e incluso el respeto a sí mismo, reconociéndose además la existencia de "bienes naturales", como la salud, la inteligencia y la imaginación.

El principal cuestionamiento a la aproximación contractualista surge del llamado velo de la ignorancia que se asume como requisito para realizar el ejercicio de la posición original de Rawls, esto debido a que cada persona que participa en un proceso de deliberación lo hace conociendo su posición en la sociedad y definiendo sus intereses particulares. Así, el velo de ignorancia representa una situación inicial de difícil validez en el mundo real.

Por último, el enfoque de capacidades y funcionamientos entiende el bienestar no como un derivado de la posesión de bienes o de la utilidad que estos generan, sino de lo que la persona logra realizar con los bienes que posee a partir de las características de estos, sus capacidades personales y el marco particular de cada decisión o acción. Desde esta perspectiva, los bienes son los medios a través de los cuales se operativizan las necesidades (Sen, 2000, 2010). Se plantean de esta manera tres conceptos fundamentales: funcionamientos, capacidades y rol de agencia. Los funcionamientos se refieren a las cosas que una persona valora ser o hacer. Las capacidades son la serie de elementos que permiten a una persona funcionar. Por su parte, el rol de agencia es la capacidad para actuar y provocar cambios, cuyos logros pueden juzgarse en función de sus propios valores y objetivos.

Esta teoría, si bien toma las preferencias individuales como la base para la elección colectiva -lo que lo acerca al utilitarismo--, plantea la necesidad de realizar una agregación sobre componentes que son heterogéneos, lo que implica homologar a una unidad común dimensiones que son difíciles de valorar, dando con ello lugar a lo que se denomina el "problema de la inconmensurabilidad".

Recientemente una ampliada variedad de acuerdos internacionales - como los ODM- han adoptado una noción del bienestar basada en el enfoque de derechos promoviendo con ello la erradicación de la pobreza como un medio para garantizar el respeto de los derechos humanos.

\section{Las mediciones del bienestar}

Las primeras definiciones del bienestar, basadas en el enfoque utilitarista, entienden que este es medible a partir de indicadores monetarios, como el PIB y PIB per cápita. Esta situación cambió a partir de la década de 1970, cuando se empezaron a considerar conceptos como la distribución y las externalidades generadas por la economía. Esto permitió el surgimiento de nuevas mediciones del bienestar que reconocían que las dimensiones materiales no daban cuenta por sí mismas del bienestar de un determinado individuo, sino que había que incorporar otros factores. De esta manera, en las últimas décadas tanto gobiernos nacionales como organismos privados, han desarrollado iniciativas que buscan medir el bienestar desde ópticas del bienestar subjetivo y concepciones ampliadas del bienestar y el desarrollo social.

En el año 2004, la Organización para la Coopera- 
ción y el Desarrollo Económico (OCDE) desarrolló el Proyecto Global sobre la Medición del Progreso de las Sociedades, diseñando a partir de este el Índice para una Vida Mejor, una herramienta interactiva que permite analizar cómo se comportan los países en función de la importancia que le asignan las personas a cada una de las variables incluidas en el indicador ${ }^{2}$.

De la misma forma, el think tank británico The New Economics Foundation (NEF) publicó en el 2006 el Índice Planeta Feliz, por medio del cual se mide el desarrollo de los países a partir de variables relacionadas con la expectativa de vida, la percepción subjetiva de la felicidad y la huella ecológica (The New Economics Foundation, 2012).

El 2008, por iniciativa del presidente francés Nicolás Sarkizy, se creó la Comisión para la Medición del Rendimiento Económico y el Progreso Social. Esta buscó identificar las limitaciones del PIB como indicador del desempeño económico y el progreso social. El informe final de la Comisión estableció ocho dimensiones que deben incluirse al medir el bienestar: ingreso, consumo y riqueza; salud; educación; actividades personales, incluyendo el trabajo; participación política; conexiones sociales; medio ambiente; y seguridad económica y física.

El Gobierno del Reino Unido, a través de la Comisión de Desarrollo Sostenible, creó la Medida Nacional de Bienestar Social. Esta no sólo busca brindar una visión complementaria a las mediciones económicas, sociales y ambientales vigentes, sino también compartir ideas y propuestas con los ciudadanos (ONS Office for National Statistics, 2014). Incorpora una serie de elementos relacionados con el bienestar subjetivo de los ciudadanos, como el nivel de felicidad, el nivel de ansiedad, el bienestar mental de la población, la existencia de una persona de apoyo y la satisfacción experimentada en una amplia variedad de dimensiones.

Más recientemente, Social Progress Imperative (SPI), una iniciativa privada encabezada por el profesor Michael E. Porter de la Universidad de Harvard, desarrolló el Índice de Progreso Social (2012). Esta iniciativa, a partir de las propuestas de Amartya Sen, Douglass North y Joseph Stiglitz, elaboró un índice basado en cincuenta y dos indicadores distribuidos en tres dimensiones relacionadas con las necesidades humanas básicas, los fundamentos del bienestar y las oportunidades. Llama la atención

\footnotetext{
${ }^{2}$ Para la construcción del "Better Life Index" la OCDE identificó once temas esenciales para el bienestar en términos de las condiciones materiales de vida (empleo, ingresos, vivienda) y la calidad de vida (comunidad, educación, balance vida-trabajo, medio ambiente, compromiso cívico, salud, satisfacción ante la vida y seguridad). Los detalles pueden consultarse en http://www.oecdbetterlifeindex.org/es/
}

que este índice no incorpore de forma directa elementos de índole económico a su medición, así como la incorporación transversalmente la problemática subjetiva en indicadores que van más allá de la satisfacción de la calidad de vida, incluyendo indicadores asociados a la satisfacción con la vivienda o la satisfacción de la demanda de métodos anticonceptivos.

Finalmente, la Comisión Económica para América Latina y el Caribe (CEPAL) plantea en el informe Panorama Social de América Latina (2013), una propuesta que, a diferencia de las anteriores, no busca crear un índice sintético del bienestar, sino un análisis a partir de tres dimensiones vinculadas con el espacio, el tiempo y la convivencia.

El espacio se refiere principalmente al medio ambiente. El tiempo hace alusión al equilibrio que se requiere para realizar distintas actividades vinculadas a la vida familiar, el trabajo, las relaciones interpersonales y el ocio. La convivencia se refiere al modo de vivir en distintos ámbitos de la vida cotidiana, tales como la familia, el trabajo y el espacio público. En su análisis, la CEPAL no incluye aspectos subjetivos por considerar que estos "no constituyen una dimensión más del bienestar, sino que lo recorren transversalmente" (CEPAL, 2013: 141).

\section{Pobreza}

\section{El concepto de pobreza: un debate en curso}

Al hablar de conceptos como bienestar o pobreza, la percepción es un componente relevante. En este sentido, las definiciones no son neutrales, sino más bien portadoras que de una carga valorativa importante, por lo que "escoger una definición en lugar de otra puede indicar no sólo preferencias académicas sino a veces inclinaciones políticas, sociales y morales" (CLACSO, 2009: 19).

Feres (2014) señala que la noción de pobreza lejos de ser clara, es más bien imprecisa, relativa, subjetiva, situacional y distributiva; por lo que lograr un consenso en torno a una única definición es, en la práctica, un ejercicio de gran complejidad. Es fundamental por lo tanto, diferenciar entre los elementos que son propios de una definición y los que son propios de una explicación del fenómeno. En el primer caso suelen estar presentes aspectos vinculados con las necesidades, las capacidades humanas y los derechos. Mientras que elementos como la vulnerabilidad, la exclusión social y la formación de capital humano, social y financiero suelen incluirse en la explicación del fenómeno. 
La Fundación para la Superación de la Pobreza (FSP) señala que la pobreza "es un fenómeno multifactorial en sus causas, multidimensional en sus manifestaciones, multiarquetípico en sus expresiones socioculturales" (Fundación para la Superación de la Pobreza, 2014: 20), presentando además una realidad dual en el sentido de que las personas en situación de pobreza no suelen estar desprovistas de todo, siendo poseedoras de una serie de activos que han sido invisibilizados o no tienen la capacidad de movilizar.

La pobreza está vinculada con la privación en dimensiones indispensables para el bienestar. En este sentido, el establecimiento de un umbral mínimo es fundamental para poder hablar de pobreza. Existen, de esta manera, una amplia variedad de planteamientos en torno a lo que se considera indispensable cuantificar para identificar una situación de pobreza. Uno de estos es el planteado por Alkire y Foster (2007), quien identificó treinta y siete propuestas desarrolladas desde distintas perspectivas, relacionadas con calidad de vida (6), dimensiones participativas y derechos humanos (5), necesidades básicas aplicadas (6), bases psicológicas de las necesidades (4), dimensiones filosóficas del valor humano (9) y estudios empíricos transculturales de bienestar y los valores universales (7).

Otro planteamiento es llevado a cabo por Spicker et al. (2009), quien realizó un estudio en el que identificó al menos doce términos asociados al concepto de pobreza, evidenciando con ello que la pobreza no tienen una única definición, sino más bien "una serie de significados relacionados a través de una serie de similitudes" (CLACSO, 2009: 292). En este ejercicio los conceptos de pobreza son agrupados en torno a una serie de condiciones materiales (necesidad, patrón de privaciones y limitación de recursos), económicas (nivel de vida, desigualdad y posición económica) y sociales (clase social, dependencia, carencia de seguridad básica, ausencia de titularidades y exclusión) de las personas existiendo en torno a ellas un juicio social -elemento articulador- que las considera moralmente inaceptables.

\section{De lo "objetivo" a lo "subjetivo"}

A comienzos de los años 1990 el Banco Mundial (BM) realizó una serie de evaluaciones de la pobreza -conocidas como "voces de los pobres"- las cuales buscaron recoger la experiencia de hombres, mujeres y niños pobres sobre lo que entienden y cómo definen la pobreza.

Los estudios permitieron concluir que en la definición de la pobreza intervienen elementos que van más allá del bienestar material. Así por ejemplo, se identificó la existencia de elementos de índole psicológico vinculados a la "falta de voz", lo que torna a las personas en situación de pobreza vulnerables "a un trato grosero, humillante e inhumano por parte tanto de los particulares como de los funcionarios públicos a quienes acuden en busca de ayuda" (Mundial, 2000: 31). La falta de infraestructura, en particular aquella relacionada con caminos y el abastecimiento de agua potable, es otro elemento relevante en la medida en que impide a las personas insertarse en la vida económica y las expone a enfermedades que podrían costarles la vida. Finalmente, se comprobó que los pobres centran su atención en la carencia de activos más que de ingresos, señalando que la "carencia de activos físicos, humanos, sociales y ecológicos está vinculada a su vulnerabilidad y susceptibilidad a los riesgos" (Mundial, 2000: 31).

Estudios como los desarrollados por el Banco Mundial han sido replicados de manera exitosa en diferentes países de la región, buscando con ello "rescatar las representaciones y significaciones que tiene el fenómeno de la pobreza para las personas que se encuentran en dicha situación" (Fundación para la Superación de la Pobreza (2010): 12).

\section{La medición de la pobreza}

La definición de lo que constituye una situación de pobreza está estrechamente vinculada con la determinación de políticas para su superación y con el establecimiento de una metodología de medición. La medición debe dar respuesta a dos preguntas fundamentales: ¿cuáles son los aspectos que se contemplan en la definición del bienestar? y ¿cuál es el mínimo razonable del bienestar? (Feres, 2014). Estas preguntas se han respondido -por lo generala través del establecimiento, por vía normativa, de ámbitos y umbrales vinculados a la insuficiencia de recursos monetarios. De esta manera, la medición de la pobreza "se ha restringido a los aspectos cuantificables y generalmente materiales de la misma" (Feres y Mancero, 2001b: 7).

Más allá del sesgo metodológico que pueda existir a favor de las necesidades materiales, Sen, 1976 plantea que cualquier metodología de medición de la pobreza debe dar cuenta de dos problemas fundamentales: a) la elección del criterio de pobreza y la determinación de aquellas personas que satisfacen o no dicho criterio (identificación); y b) la medida de la extensión de la pobreza (agregación).

En términos generales, la identificación de las personas en situación de pobreza implica realizar una comparación de los niveles de bienestar que 
experimentan quienes forman parte de un determinado grupo social, estableciendo los criterios que permitan distinguir si una persona se ubica por debajo del umbral mínimo definido por la sociedad en un momento determinado. El consumo y el ingreso son los indicadores más aceptados para limitar los niveles de bienestar, no sólo por la vinculación que se establece entre el nivel de vida y la satisfacción de necesidades materiales, sino también por la disponibilidad de información asociada a los mismos. Sin embargo, no se puede "declarar a una variable como superior a la otra para representar el bienestar de las personas" (Feres y Mancero, 2001b: 14).

La agregación debe, no solo reunir los datos de las personas en situación de pobreza en un indicador general, sino también permitir comparaciones entre las diversas situaciones, evaluando con ello el impacto de las políticas destinadas a la superación de la pobreza. La complejidad del ejercicio recae en la posibilidad de resumir las múltiples dimensiones de la pobreza en un valor único sin ocultar elementos del fenómeno que resulten de interés para la el diseño de las políticas.

\section{Metodologías para la medición de la pobreza}

Las mediciones de la pobreza se clasifican en directas e indirectas. Las primeras verifican que la persona (hogar) logre satisfacer efectivamente sus necesidades básicas o bien que tenga acceso a los distintos satisfactores que requiera para cubrir sus necesidades. Las segundas consideran que una persona (hogar) es pobre cuanto no tiene los recursos suficientes para adquirir los bienes y servicios que necesita. En este último caso, es suficiente con tener la capacidad de realizar la compra o el consumo, sin que se verifique que estos sean efectivamente realizados.

El método de la línea de pobreza $(\mathrm{LP})^{3}$, representa en términos generales el monto mínimo del ingreso (gasto) requerido para mantener un nivel de vida adecuado según el estándar de vida de una sociedad en particular. Estas líneas pueden construirse a través de distintas metodologías, siendo el costo de las necesidades básicas - canasta de satisfactores-el más utilizado.

Las líneas de pobreza pueden plantearse desde un enfoque objetivo o subjetivo. El primero incluye las líneas de pobreza absoluta y relativa, mientras que el segundo incluye las líneas de pobreza subjetiva.

En las líneas de pobreza absolutas se asume que el valor real de la canasta de satisfactores es cons-

\footnotetext{
${ }^{3}$ Además de la LP se acostumbra calcular la línea de pobreza extrema o línea de indigencia (LI).
}

tante a lo largo del tiempo, por lo que esta sólo debiera ajustarse por los cambios en los precios de los bienes y servicios. No considera que los patrones de consumo y los satisfactores de necesidades puedan variar en el tiempo.

Por su parte, en las líneas de pobreza relativas, el corte se fija en relación a los ingresos medios de un país, utilizando para ello como parámetro el $50 \%$ o $60 \%$ de la mediana, el $50 \%$ de la media, o bien un parámetro de la distribución del ingreso. Los datos surgen de observación de la realidad y no de una construcción normativa.

A través del método de las necesidades básicas insatisfechas (NBI) se busca verificar si las personas (hogares) han sido capaces de cubrir una serie de necesidades básicas que les permitan vivir una vida digna, identificando como pobres a aquellos que no logran satisfacer dichas necesidades.

El análisis de NBI requiere desarrollar varios pasos previos relacionados con la determinación de las necesidades básicas susceptibles de estudio; la determinación de las dimensiones que constituyen la privación; la elección de los indicadores por medio de los cuales se miden las dimensiones elegidas; la definición de los umbrales por debajo de los cuales se establece que existe una carencia; y la verificación de la representatividad de los indicadores a las situaciones de pobreza, identificándose finalmente a los pobres a través del conteo de sus privaciones.

Al hablar de necesidades, según lo señalado por Feres y Mancero (2001a), es posible distinguir entre necesidades absolutas y relativas. Las primeras se consideran indispensables para la existencia humana independientemente del medio en que se desarrolle la persona, mientras que las segundas se vinculan con las privaciones relativas que experimenta una persona en su condición de miembro de una determinada sociedad.

La selección de las necesidades básicas suele estar determinada en la práctica por la información disponible en los censos, siendo el acceso a una vivienda que asegure un estándar mínimo de habitabilidad, el acceso a servicios sanitarios básicos, el acceso a educación básica y la capacidad económica para alcanzar un determinado nivel de consumo las categorías más utilizadas.

La posibilidad de identificar situaciones de pobreza con un alto grado de desagregación y la existencia de fuentes de información consolidadas, son algunas de las fortalezas del método NBI. Sin embargo, entre sus debilidades se citan la periodicidad con que se obtiene la información, el grado de precisión de los mapas de pobreza y su limitación para identificar situaciones de pobreza recientes, por lo 
que se considera que es más adecuado para identificar los rasgos descriptivos de la pobreza.

Algunos autores han intentado superar las limitaciones de este método través del uso conjunto de los resultados obtenidos en NBI y LP, dando con ello origen a una medición bidimensional de la pobreza. Kaztman y Gerstenfeld, 1988 proponen una clasificación en la que los hogares pueden clasificarse en situación de pobreza crónica (existen carencias en ingresos y necesidades básicas, por lo que sufren exclusión social), en pobreza reciente (movilidad social descendente), en pobreza inercial (hogares que no son pobres bajo LP pero que arrastran alguna carencia de tipo NBI), y hogares en condiciones de integración social (viven una vida digna), siendo esto una clasificación que, en el mejor de casos, se utiliza como complemento de las mediciones basadas en indicadores monetarios.

\section{Metodología}

Se realizó un estudio con un enfoque cuantitativo, con alcance descriptivo-exploratorio de diseño no experimental. Un estudio descriptivo permite mostrar con precisión las dimensiones de un fenómeno, mientras que un diseño no experimental permite "observar fenómenos tal y como se dan en su contexto natural, para posteriormente analizarlos" (Hernández et al., 2010: 149).

A partir de la revisión bibliográfica y del análisis de la propuestas oficiales desarrolladas en América Latina se construyó un instrumento que permite medir la pobreza dando cuenta de la multidimensionalidad del fenómeno, pudiéndose analizar la incidencia de cada dimensión en el cálculo de la pobreza total.

\section{La medición multidimensional de la pobreza}

El uso de indicadores monetarios para la medición de la pobreza no impide la adopción de medidas multidimensionales que permitan, de manera más efectiva, abordar un fenómeno que es complejo y dinámico en todas sus formas. Denis et al. (2010) plantean que las mediciones multidimensionales de la pobreza pueden clasificarse en dos grandes grupos:

Formulaciones no axiomáticas: entre las que se incluye el Índice de Necesidades Básicas Insatisfechas (INBI), el Índice de Pobreza Humana (IPM), los análisis de componentes principales, y los índices de privaciones ${ }^{4}$.

Hoy por hoy, la propuesta de Alkire y Foster es la metodología que tiene el mayor grado de aceptación, tanto por parte de los gobiernos nacionales como de varios organismos internacionales involucrados en el combate a la pobreza.

\section{La propuesta de Alkire y Foster (2007).}

El primer aspecto a destacar de la metodología de Alkire y Foster es su simplicidad. El Oxford Poverty and Human Development Initiative (OPHI) afirma que este es un método intuitivo y fácil de calcular, al punto que puede introducirse través de doce pasos sucesivos, siendo los primeros seis comunes a distintas mediciones de pobreza multidimensional, y los seis restantes propios de esta metodología.

Según Alkire y Foster en la investigación de la pobreza multidimensional se ha intentado desarrollar una metodología análoga a la unidimensional, prestándole mayor atención al problema de la agregación principalmente por medio de la "extensión" de los axiomas unidimensionales de medición a una variedad de mediciones multidimensionales, dejando con ello en un segundo plano el problema de la identificación, lo que implica de alguna forma ignorar que este es un elemento "implícito en todas las mediciones de la pobreza" (Alkire, 2007: 1).

Para superar esta postura, los autores proponen una metodología de medición multidimensional basada en un método comprensivo de identificación denominado punto de corte dual. Este consiste en la existencia de una línea de corte dual, dentro de las dimensiones $\left(z_{j}\right)$ y entre las dimensiones $(k)$, siendo una persona (hogar) identificada finalmente como pobre multidimensional cuando la cantidad de dimensiones en las que sufre privaciones es por lo menos $\mathrm{k}^{5}$. Es importante señalar que si bien no existe un método determinístico para definir el valor del parámetro k, en la práctica dicho valor ha sido definido a través de métodos estadísticos.

\footnotetext{
${ }^{4}$ Formulaciones axiomáticas: entre las que se incluyen los modelos de Bourguignon y Chakravarty (2003), Chakravarty, Deutsch y Silber (2005), Chakravarty y D'Ambrosio (2006), Alkire y Foster (2007), Bossert, Chakravarty y D'Ambrosio (2009), y la adaptación del modelo de Alkire y Foster realizada por CONEVAL de México (2009).

${ }^{5}$ Según los autores, la primera línea de corte puede ser considerada como una "línea tradicional de pobreza o línea de corte basada en dimensiones específicas, que identifica si una persona sufre privaciones en relación con esa dimensión" (Alkire, 2007:2), mientras que la segunda línea de corte "marca cuán amplias deben ser las privaciones que sufre una persona para ser considerada pobre" (Alkire, 2007:2).
} 
En lo que respecta a la agregación de las personas en situación de pobreza multidimensional, los autores proponen una serie de medidas derivadas de los indicadores del tipo FGT -desarrollados por Foster, Greer y Thorbecke en 1984- pero ajustados a las dimensiones, lo que permite satisfacer una serie de axiomas que son deseables en una buena medida de la pobreza.

En este sentido, se proponen las siguientes medidas de la pobreza multidimensional:

- Tasa de recuento: identifica el número de personas que es multidimensionalmente pobre. Se conoce también como incidencia de la pobreza $(\mathrm{H})$.

- Intensidad de la pobreza: el promedio ponderado de las privaciones (carencias) que sufre la población identificada como pobre. Se conoce también como el alcance promedio de las privaciones $(\mathrm{A})$.

- Tasa de recuento ajusta a las dimensiones: definida a partir de la combinación del número de personas pobres y la proporción de privaciones $\left(M_{0}=H * A\right)$.

- Brecha de pobreza ajustada: introduce el concepto de magnitud promedio de las privaciones (G) para estimar la brecha promedio de pobreza $\left(M_{1}=H * A * G\right)$.

- Severidad promedio de las privaciones: permite considerar el impacto que genera una privación moderada en comparación con una más grave $\left(M_{2}=H * A * S\right)$.

Estas mediciones satisfacen una serie de propiedades axiomáticas como descomponibilidad, invarianza de replicación, simetría, enfoque de pobreza y privaciones. En el modelo se le suele asignar el mismo peso ponderado a cada dimensión. Según los autores esto es conveniente cuando no existen motivos para considerar que una dimensión es más importante que otra, o bien cuando son seleccionadas intencionalmente para que tengan el mismo peso relativo. Sin embargo, agregan, existen argumentos válidos que justifican que el peso relativo es un "juicio de valor normativo, y por tanto debería estar abierto al debate y el escrutinio público" (Alkire, 2007: 28).

Finalmente, Alkire y Foster reconocen que el modelo presenta algunas limitaciones al querer utilizar tanto datos ordinales como cardinales en algunas de las medidas $\left(M_{a}\right)$, esto debido a que al dicotomizar algunas dimensiones de tipo cardinal, se corre el riesgo de perder información importante, siendo necesario el uso de otras herramientas que permitan superar esta limitación. Lo anterior podría lograrse utilizando "ponderaciones diferentes para cada dimensión" (Alkire, 2007: 27).

\section{Colombia: Índice de Pobreza Multidi- mensional}

En la actualidad Colombia cuenta con dos mecanismos oficiales para medir la pobreza: el primero a partir de los ingresos monetarios de los hogares (LP y LI) y el segundo por medio de un índice de pobreza multidimensional (IPM) el cual evalúa la calidad de vida en cinco dimensiones distintas al ingreso. Ambas mediciones son complementarias entre sí.

Con la oficialización de estas dos metodologías, el Estado colombiano pretende no sólo "asegurar la transparencia, oportunidad y credibilidad de las cifras de pobreza" (CONPES, 2012: 5) sino también crear los arreglos institucionales que le permitan garantizar la continuidad de ambas metodologías.

Según CONPES (2012) la adopción del IPM implica tomar una serie de decisiones de índole metodológica que requieren de un proceso de análisis serio y responsable, lo que no implica la ausencia de juicios de valor por parte del investigador. En este sentido, se definió como unidad de análisis al hogar en lugar de la persona, debido a que las privaciones que sufre un hogar son experimentadas de forma simultánea por las personas que lo conforman, lo que implica que "los agentes maximizan como hogar" (Bustamante, 2013: 7), siendo las oportunidades y logros de un individuo determinadas en función de las capacidades de dicho hogar.

Con esta decisión se buscó compatibilizar la orientación y el diseño de los instrumentos de política pública dirigidos a la reducción de la pobreza, siendo según Angulo et al. (2011) tres las justificaciones puntuales que se plantean al respecto:

- La garantía de condiciones de vida digna no está dada por la responsabilidad de los individuos de forma aislada.

- La protección social se enfoca en la familia.

- En Colombia existe evidencia empírica acerca de la respuesta del hogar en situaciones adversas y no de los individuos de forma aislada.

En lo que respecta a la definición de las dimensiones, indicadores y puntos de corte, esta se realizó a partir de la revisión de las variables de uso frecuente 
en otros indicadores aplicados en Latinoamérica ${ }^{6}$, la Constitución Política de Colombia, las dimensiones y variables usadas en otros índices multidimensionales aplicados en el país (NBI, ICV, SIS$\mathrm{BEN}$ ), los estudios de voces de los pobres de Colombia, los umbrales definidos por los ODM (Colombia), las políticas sectoriales, la discusión con expertos, y la disponibilidad de información en una sola fuente estadística. Esta última proporcionada por la Encuesta de Calidad de Vida (ECV) que elabora el Departamento Administrativo Nacional de Estadísticas (DANE).

De igual forma, Bustamante (2013) señala que en la selección final buscó que los indicadores tuvieran una relación directa con la política social desarrollada por el Estado, de manera que los mismos fueran susceptibles de modificación por medio de las políticas públicas.

El IPM utiliza, según Angulo et al. (2011), una estructura de ponderación anidada en la que cada dimensión tiene el mismo peso, lo mismo que cada variable a lo interno de cada dimensión. El punto de corte (k), a partir del cual una persona es identificada como pobre multidimensional, fue establecido a partir de la consideración de una serie de criterios estadísticos de elección. Se observó el número de privaciones que experimentan diferentes grupos de la población, acordándose finalmente el número de privaciones en $\mathrm{k}=5 / 15$, lo que implica que un hogar es considerado como multidimensionalmente pobre cuando sufre privaciones en al menos un $33 \%$ de las variables seleccionadas.

Una vez realizado el ejercicio de medición, Angulo et al. (2011) identifican diversos temas que será necesario explorar a futuro, tal es caso de la posibilidad de incluir variables que midan la calidad de los servicios más allá de la cobertura de los mismos, la necesidad de incluir variables relacionadas con la calidad del empleo, y la conveniencia de incluir en las privaciones del índice aspectos relacionados con la seguridad, la dignidad y el bienestar subjetivo.

Finalmente, se reconoce que la construcción de un indicador está fuertemente limitada por la disponibilidad de información que se tenga en las encuestas. Es, por lo tanto, necesario "avanzar hacia el ajuste de las fuentes de información" existentes (Angulo et al., 2011: 34), con miras a garantizar la pertinencia de los indicadores utilizados en el índice de pobreza multidimensional.

\footnotetext{
${ }^{6}$ Como el IDH, IPM, Índice de Condiciones Subjetivo, Índice Cohesión Social (CEPAL), Índice de Oportunidades Humanas (Banco Mundial) y el Índice Disímil de la Universidad de Oxford.
}

\section{México: más allá de la propuesta de Alkire y Foster}

Hasta hace poco, México contó con una medida oficial de la pobreza basada en indicadores monetarios. Sin embargo, con la promulgación en el 2004 de la Ley General de Desarrollo Social (LGDS) se adopta una noción de pobreza que se manifiesta en múltiples espacios vinculados con el bienestar económico, los derechos sociales y el contexto territorial, siendo estos espacios a través de los cuales se buscó garantizar el ejercicio pleno de los derechos sociales consagrados en la Constitución Política de dicho país.

El espacio de bienestar económico comprende las necesidades asociadas a los bienes y servicios que pueden ser adquiridos por la población mediante el ingreso. Por su parte, el espacio de los derechos sociales se define a partir de las carencias sociales que experimenta la población en el ejercicio de sus derechos para el desarrollo social. Finalmente, el espacio del contexto territorial incorpora una serie de aspectos vinculados con el grado de cohesión social.

Los indicadores de desarrollo social deben dar cuenta al menos del rezago educativo promedio en el hogar; el acceso a los servicios de salud; el acceso a la seguridad social; la calidad y espacios de la vivienda; el acceso a los servicios básicos en la vivienda; el acceso a la alimentación; el grado de cohesión social; y el grado de accesibilidad a carretera pavimentada. Dichos indicadores son interpretados como los elementos mínimos sin los cuales una persona no ejerce o no puede ejercer sus derechos sociales.

La existencia de una carencia en el criterio asociado al bienestar económico se define a partir de la comparación del ingreso mensual per cápita del hogar con el valor de una la línea de bienestar y una línea de bienestar mínimo, mientras que las carencias sociales se identifican por medio de una serie de indicadores agrupados en un índice sintético, denominado Índice de Privación de Derechos Sociales (IPDS).

En las mediciones mexicanas la unidad de análisis es, por lo general, la persona, considerándose el hogar (vivienda) en aquellos casos en los que no es posible establecer una medida a nivel individual, lo que implica asignarle el mismo valor a todas aquellas personas que ocupan una misma vivienda.

Para la determinación de los umbrales se siguió, de manera sucesiva, algunos de los siguientes procesos: verificar y aplicar la normativa legal; emplear el criterio experto de las instituciones públicas especialistas en la materia del indicador; utilizar crite- 
rios basados en resultados de análisis estadísticos; y finalmente, la determinación a lo interno de la autoridad competente (CONEVAL, 2011).

Siguiendo la propuesta de Alkire y Foster, el IPDS considera una línea de corte dual, asignándole a cada una de las dimensiones la misma importancia relativa, identificando a una persona como pobre en dicha dimensión cuando el valor del índice es mayor a cero $(k=C=1)$. A partir de este resultado, y de manera análoga, se define un umbral de privación extrema $\left(k^{*}=C^{*}=3\right)$, siendo este umbral determinado a través de distintos métodos estadísticos.

Es a partir de la existencia de carencias en el espacio asociado al bienestar económico y los derechos sociales que se identifican las personas en situación de pobreza multidimensional, siendo estas definidas como "aquéllos cuyo ingreso corriente total per cápita estimado es inferior al valor de la línea de bienestar y que padecen al menos una carencia social" (SEDESOL, 2013: 5), estableciéndose a partir de la combinación de los resultados obtenidos en dichos espacios la siguiente clasificación:

- Pobres multidimensionales: población con ingreso inferior al valor de la línea de bienestar y que padece, al menos, una carencia social (cuadrante I). Dentro de este grupo se incluyen las personas en situación de pobreza multidimensional moderada y pobreza multidimensional extrema, siendo estos últimos delimitados en términos gráficos por el área comprendida entre la línea de bienestar mínimo y el umbral de privación extrema (sub cuadrante I*).

- Vulnerables por carencias sociales: población que presenta una o más carencias sociales a pesar de que poseer los recursos monetarios para adquirir los bienes y servicios considerados como necesarios (cuadrante II). Se consideran hogares pobres por criterio de carencias sociales.

- Vulnerables por ingresos: población que no presenta carencias sociales, pero cuyo ingreso es inferior o igual a la línea de bienestar (cuadrante III). Se denominan hogares pobres por criterio de bienestar económico.

- No pobre multidimensional y no vulnerable: población cuyo ingreso es superior a la línea de bienestar y que no tiene carencia social alguna (cuadrante IV).

En lo que respecta a la medida agregada de la pobreza, la CONEVAL (2011) define en su metodología tres tipos de medidas: medidas de incidencia, medidas de profundidad y medidas de intensidad, mismas que son determinadas a partir de la metodología establecida por Alkire y Foster.

Es importante señalar que la pertinencia de las mediciones desarrolladas a partir de esta nueva metodología se apoya en una mejoría de las fuentes de información existentes. En este sentido, la implementación de un Módulo de Condiciones Socioeconómicas (MDC) en la Encuesta Nacional de Ingresos y Gastos de los Hogares (ENIGH), permitió no sólo obtener información útil y confiable sobre los distintos indicadores de medición de la pobreza, sino también garantizar la continuidad de los datos de la encuesta elaborados por la Instituto Nacional de Estadística y Geografía (INEGI).

Finalmente, la CONEVAL (2011) ha reiterado en varias ocasiones la importancia de contar con información que sea actualizable en el tiempo, lo que presenta dos grandes retos. El primero, que algunas condiciones y criterios que hoy son pertinentes, pueden dejar de serlo en lo futuro. El segundo, la necesidad de ofrecer cierta continuidad a las mediciones efectuadas a través de las metodologías establecidas, lo que permitiría no sólo consolidar dichas mediciones sino también que las mismas sean conocidas y aceptadas por el público en general.

\section{Chile: una propuesta para ampliar la medición de la pobreza}

El año 2012 por mandado del entonces Presidente de la República, Sebastián Piñera Echenique, se conforma la Comisión Presidencial para la Medición de la Pobreza (CPMP) con la finalidad de actualizar la medición de la pobreza monetaria, proponer una medida multidimensional de la pobreza, y establecer cambios en la institucionalidad para la medición de la pobreza, todo esto bajo la premisa de que "visibilizar la pobreza y hacerla objeto prioritario de la política pública requiere, en primer instancia, poder cuantificarla y caracterizarla" de manera adecuada (Comisión Presidencial para la Medición de la Pobreza, 2014: 6).

En este sentido, la Comisión propone complementar la medida monetaria de la pobreza con una medición multidimensional, siendo en este caso la unidad de análisis el hogar, esto en el entendido de que es allí en donde se "responde a la crisis y se despliegan acciones que permitan hacerle frente a las dificultades" (Comisión Presidencial para la Medición de la Pobreza, 2014: 9). En lo que respecta a la definición de las dimensiones a incluir en el índice sintético la Comisión recurre al uso de criterios de índole normativa, subjetiva y de disponibilidad de información. 
Figura 1: Identificación de los pobres multidimensionales en México
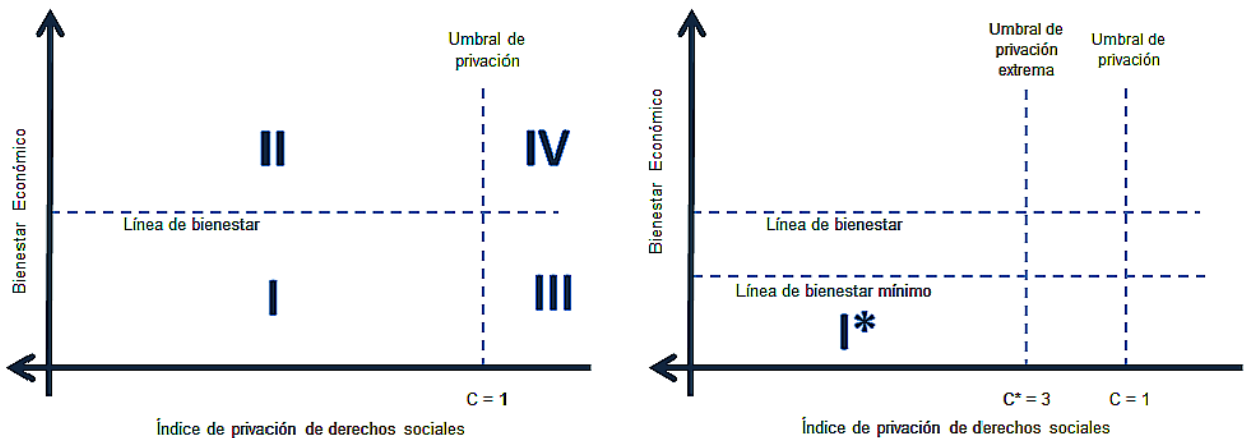

Fuente: Elaboración propia en base a datos de CONEVAL (2010, 2011)

En los criterios normativos se consideró que la dimensión propuesta fuera un elemento constituyente del bienestar, lo que implica la incidencia de esta sobre la calidad de vida de las personas. Sin embargo, descartó el uso de mediciones subjetivas del bienestar por considerar que "la medición de pobreza da lugar a acciones de política pública y que los aspectos subjetivos del bienestar pueden estar afectos a preferencias y predisposiciones que no necesariamente deben ser objeto de compensaciones públicas" (Comisión Presidencial para la Medición de la Pobreza, 2014: 74).

Se consideró además que la obtención del estándar mínimo aceptable en cada dimensión fuera alcanzable a través de bienes y servicios que no se obtienen mayoritariamente en el mercado, lo que implica la existencia de una carencia que trasciende la falta de ingresos.

En lo que respecta al elemento subjetivo, se le dio una especial atención a los resultados del estudio "Voces de la pobreza" (2010), elaborado por la Fundación para la Superación de la Pobreza (FSP), en la medida en que el mismo contiene la valoración y percepción de las personas que viven en situación de pobreza sobre las dimensiones que más los afec$\tan$.

El índice sintético propuesto por la Comisión utiliza una estructura de ponderación anidada. El uso de un índice sintético, según lo señalado por la Comisión, es más efectivo para comunicar las variaciones en los niveles de pobreza, por lo que siguiendo la metodología de Alkire y Foster se recomendó identificar como pobres multidimensionales a aquellos hogares que tengan al menos un $\mathrm{k}=33 \%$ de carencias respecto del total de indicadores incluidos en la medición. En todos los casos se buscó que los indicadores pudieran ser susceptibles de modificación a través de las políticas públicas.

A partir del uso de los resultados obtenidos en las mediciones monetarias y multidimensionales de la pobreza, la Comisión propuso distinguir entre distintos niveles de bienestar:

- Hogares en situación de pobreza: aquellos que tienen ingresos por debajo de la línea de pobreza (sólo considera una medida monetaria de la pobreza).

- Hogares en situación de pobreza extrema: tiene ingresos por debajo de la línea de pobreza, y experimentan privaciones sociales por encima del umbral.

- Hogares en situación de vulnerabilidad: cuentan con ingresos por encima de la línea de pobreza, pero por debajo de la línea de vulnerabilidad o con privaciones sociales por encima del umbral.

- Hogares que no están en situación de pobreza ni vulnerabilidad: tienen ingresos por encima de la línea de vulnerabilidad, así como carencias por debajo del umbral.

Las Comisión considera que las fuentes de información son indispensables para garantizar la representatividad de las mediciones. En este sentido, se señala la necesidad de reforzar las fuentes de información existentes, siendo en este sentido la periodicidad con que se recabe dicha información indispensable para garantizar la pertinencia de las mediciones.

Finalmente, se señala la necesidad de realizar estudios complementarios que permitan enriquecer el análisis y eventualmente incorporar nuevas dimensiones a la medición multidimensional. En este sentido, se plantea una agenda de estudios complementarios que contenga, entre otras cosas, estudios de panel, estudios cualitativos sobre la realidad de los hogares, estudios sobre la percepción de las personas en situación de pobreza, y estudios sobre la dinámica y determinantes del ingreso. 


\section{CEPAL: una medición de la pobreza ampliada}

Finalmente, resulta de interés observar la propuesta que la CEPAL plantea en el Informe Panorama Social de América Latina (2013), mismo que desde una perspectiva multidimensional, ofrece una visión distinta del bienestar, reconociéndose la necesidad de contar con enfoques novedosos que proporcionen una mirada ampliada del desarrollo social, lo que permitiría lograr un diseño más integral de las políticas públicas.

La CEPAL reconoce que existen aspectos ampliamente debatidos en torno al análisis de la pobreza multidimensional, esto permite desarrollar "mejores condiciones para la realización de estas mediciones" (CEPAL, 2013: 60). Sin embargo, no puede obviarse la existencia de limitaciones de índole político y de acceso a la información, las cuales dificultan la puesta en marcha de un ejercicio de medición de esta naturaleza.

Lo anterior implica que al momento seleccionar las dimensiones, indicadores y umbrales, así como al combinarlos en un índice sintético, deben formularse y explicitarse los argumentos que justifiquen la selección, lo que no implica llegar a un "concepto acabado de pobreza" (CEPAL, 2013: 61) sino más bien a establecer los criterios de decisión a partir de los cuales se orientará la toma de decisiones al momento de desarrollar una medición multidimensional.

En su propuesta, la Comisión visualiza el bienestar a partir de un enfoque de derechos, de capacidades y de necesidades básicas insatisfechas. Considera que los instrumentos y la información disponible no permiten establecer distinciones claras entre una u otra privación, pudiendo estas ser interpretadas de manera simultánea "como aproximaciones a la vulneración de derechos, como restricciones a la satisfacción de necesidades o como obstáculos para el logro de funcionamientos" (CEPAL, 2013: 62).

Se utiliza al hogar como unidad de análisis debido a que considera que esta es "la entidad básica donde se toman las decisiones más relevantes para la satisfacción de necesidades y el logro de funcionamientos" (CEPAL, 2013: 62). Sin embargo, dadas las dificultades metodológicas y la limitación en los datos, no considera las asimetrías que puedan existir a lo interno de estos.

Para el desarrollo del ejercicio de medición, la CEPAL propone como punto de partida un análisis basado en indicadores de carencias críticas de tipo NBI, siendo la inclusión de elementos relacionados con la "pobreza de energía", como la falta de electricidad y el uso de combustible tóxico para cocinar, los elementos más novedosos en comparación con ejercicios similares del tipo NBI.

Se reconoce en este punto la necesidad de incluir aspectos vinculados con la situación nutricional, el estado de salud, los sistemas de eliminación de basura, y la situación de empleo de las personas, entre otras. Sin embargo, además de la inexistencia de datos, surgen dificultades vinculadas con la definición de los umbrales mínimos, una situación que requiere de un proceso de diálogo interdisciplinario para poder emitir un criterio válido para la medición de la pobreza.

Una vez definidas las dimensiones, indicadores y umbrales de carencias, el ejercicio de la CEPAL sigue la metodología de identificación propuesta por Alkire y Foster, estableciéndose en este sentido un umbral por dimensión, así como un umbral multidimensional $(\mathrm{k}=20 \%)$. Finalmente, se calculó la incidencia de la pobreza multidimensional a partir de índice de recuento $(H)$, la intensidad de la pobreza $(A)$, y el Índice de recuento ajustado $\left(M_{0}\right)$.

En una segunda fase del ejercicio, se agregó una medida monetaria al índice construido a partir de los indicadores de NBI, con la intención de mejorar la identificación de los hogares en situación de pobreza. El indicador de ingresos utilizado es la línea de indigencia, que se utiliza en lugar de la pobreza monetaria a fin de minimizar la posibilidad de doble conteo.

Son dos son las conclusiones a las que es posible arribar en esta etapa del ejercicio. La primera se relaciona con el hecho de que se mantiene la robustez del resultado, esto no sólo en la medida en que se mantiene el ordenamiento de los países analizados, sino también el resultado de las pruebas estadísticas, como la redundancia y el grado de similitud, lo que indica que "la agregación de una dimensión monetaria a un índice multidimensional de pobreza tiene potencial para reducir vacíos de información y disminuir los errores de exclusión" (CEPAL, 2013: 74).

La segunda conclusión se relaciona con el hecho de que en los datos se observa una disminución en la incidencia de la pobreza multidimensional, siendo esta una situación que no se condice con la realidad observada en la región, lo que evidencia, según lo señalado por la CEPAL (2013), la pérdida de capacidad de los indicadores basados en NBI para identificar a los pobres.

A fin de poder solucionar esta última situación, la CEPAL plantea la necesidad de incorporar en la medición indicadores que den cuenta de la exclusión y la vulnerabilidad que sufren las personas producto 
de la marginación de las instituciones, una noción poco convencional en mediciones de la pobreza, y que viene a reconocer el hecho de que la desvinculación de las instituciones que estructuran el paso de la niñez a la adultez y luego a la vejez, representan un mayor riesgo de pobreza o exclusión.

En esta última etapa del ejercicio, denominada "medición ampliada de la pobreza", se establece un umbral multidimensional de $\mathrm{k}=10 \%$, mientras que a cada dimensión e indicador se les asigna el mismo peso ponderado.

\section{Una propuesta exploratoria pa- ra Costa Rica}

El combate a la pobreza si bien ha estado presente de manera permanente en la agenda pública del Estado costarricense, ha demostrado que bajo las concepciones actuales no es capaz de cumplir con los objetivos propuestos, siendo necesaria la construcción de alternativas que permitan, desde una óptica distinta, alcanzar las condiciones mínimas requeridas para garantizar el desarrollo humano.

\section{Una propuesta exploratoria}

La Constitución Política representa el acuerdo social fundamental de la sociedad costarricense. En ella es posible identificar aquellas áreas en las que el legislador ha manifestado un interés particular, permitiendo a partir de esto legitimar ciertas dimensiones dentro de la propuesta exploratoria para la construcción de un índice sintético multidimensional.

En el Título V de la Constitución de Costa Rica, denominado Derechos y Garantías Sociales, se establece que el Estado deberá procurar el mayor bienestar a todos los habitantes del país, lo que implica el derecho a un ambiente sano y equilibrado (artículo 50), a una ocupación honesta y útil (artículo 56), a un salario que le procure bienestar y existencia digna a las personas (artículo 57), a una jornada ordinaria de trabajo que no exceda las de ocho horas diarias (artículo 58), a la vivienda y la creación del patrimonio familiar (artículo 65), a la protección de los desocupados involuntarios y su reintegración al trabajo (artículo 72), a la seguridad social (artículo 73), así como cualquier otro derecho y beneficio que derive de los principios de justicia social (artículo 74).

Por su parte, el Título VII, denominado Educación y Cultura, señalada que la educación pública debe ser organiza como un proceso correlacionado en sus distintos ciclos, siendo en este sentido la educación preescolar y la general básica obligatorias, gratuitas y costeadas por el Estado (artículo 78). Se establece además que el Estado patrocinará y organizará la educación de adultos con miras a combatir el analfabetismo y proporcionar oportunidades culturales a quienes las deseen (artículo 79).

Más recientemente en documentos del Ministerio de Planificación Nacional y Política Económica (MIDEPLAN), como el Proyecto Bicentenario (2012) y Costa Rica 2030 (2013), se definen una serie de metas y objetivos en función de los desafíos de desarrollo de largo plazo que enfrenta el país, estableciéndose que los mismos deben garantizar el disfrute pleno del bienestar, lo que implica "asegurar la calidad de vida en el presente y su sostenibilidad en el futuro" (MIDEPLAN, 2013: 18), siendo dichos planteamientos legitimados a través de un proceso de consulta ciudadana realizado por el Ministerio.

A partir de estos antecedentes, se definieron siete áreas prioritarias para el desarrollo nacional: el crecimiento económico; el equilibrio de las finanzas públicas; la infraestructura; la inversión social y cultural; la reducción de las desigualdades; el fortalecimiento de la democracia; y el medio ambiente y la seguridad energética.

En cada una de estas áreas se establecieron metas específicas, siendo algunas de ellas vinculadas con el desempleo y subempleo (insuficiencia de horas), el rezago educativo, el logro educativo (secundaria completa), la tasa de escolaridad, el acceso universal a Internet, eliminar el vertido de aguas servidas sin tratamiento a los sistemas naturales, la disposición final de los desechos sólidos con un mínimo de impacto ambiental, el aumento en la disponibilidad de vivienda y de zonas verdes recreativas, el uso de las tecnologías de la información y la comunicación (TIC) en el proceso de aprendizaje $(100 \%)$, la conexión a Internet de banda ancha (100\%), la cobertura de los sistemas de seguridad social (100\%), la universalización de la cobertura de pensiones (incluyendo los adultos mayores), la erradicación de los asentamientos en precarios (tugurios), la mejora en la calidad del aire, y la conservación de la biodiversidad, entre otros.

\section{Selección de dimensiones, indicadores y umbrales}

La definición de las dimensiones, indicadores y puntos del corte utilizados en la propuesta exploratoria de medición multidimensional de la pobreza se realizó a partir de la revisión de las variables de 
uso frecuente en indicadores desarrollados de manera oficial en Colombia y México, y de manera exploratoria en Chile y CEPAL; también se consideraron los derechos fundamentales establecidos en la Constitución Política; y las metas prioritarias definidas por el MIDEPLAN en los Proyecto Bicentenario (2012) y Costa Rica 2030 (2013). Todo esto sujeto a la información disponible en la Encuesta Nacional de Hogares (ENAHO) aplicada por el Instituto Nacional de Estadística y Censos (INEC) de 2010 a 2013.

En todos los casos se buscó que las dimensiones fuera susceptible de modificación a través de las políticas públicas, y que reflejaran las actuales condiciones de vida de los habitantes del país, siendo posible su modificación o reforzamiento a medida que mejoren las fuentes de información requeridas para la realización de la medición.

Siguiendo la propuesta de la CEPAL (2013), se realizó un análisis previo en el que se evaluaron una serie de indicadores comúnmente utilizados en mediciones de necesidades básicas. En este sentido, Méndez y Bravo (2014) desarrollaron a partir de las metodologías de NBI y LP diversos mapas de carencias críticas con los datos del Censo Nacional de Población y Vivienda de 2011, utilizando para ellos dimensiones vinculadas con el acceso a albergue digno, el acceso a vida saludable, el acceso a conocimiento, y el acceso a otros bienes y servicios. Dicho ejercicio utilizó el hogar como unidad de análisis, identificando como pobres a aquellos que presentan una carencia en al menos uno de los criterios definidos en las dimensiones. A cada dimensión se le asignó la misma ponderación, lo que implica que el valor de los indicadores se definió en función de la cantidad de los mismos en una dimensión.

Dos fueron las conclusiones obtenidas en este análisis previo. En primer lugar, se confirmó el hecho de que el porcentaje de hogares con una o más carencias de tipo NBI no es necesariamente el mismo de los hogares que son identificados como pobres bajo el método de LP, lo que corrobora una vez más que el bienestar y la pobreza son situaciones que van más allá de los indicadores monetarios, por lo que resulta fundamental para la superación de la pobreza poder contar con herramientas que den cuenta de la multidimensionalidad asociada a dicho fenómeno.

En segundo lugar, se confirmó que algunos indicadores utilizados en las mediciones de tipo NBI evidencian signos claros de agotamiento, por lo que los mismos no fueron considerados como representativos de una situación de pobreza al momento de seleccionar los indicadores multidimensionales. Lo anterior se produce principalmente como conse- cuencia del aumento en la cobertura de los servicios básicos, principalmente vinculados con el agua potable y la luz eléctrica, por lo que su uso aportaría muy poco al índice sintético de pobreza multidimensional ${ }^{7}$.

En total se definieron nueve dimensiones vinculadas con el albergue digno, los servicios públicos domiciliarios, las tecnologías de la información y la comunicación, la vida saludable, el medio ambiente, la educación básica, la exclusión social, la calidad del empleo y la seguridad social. El detalle de las mismas se presenta a continuación.

\section{Dimensión 1: albergue digno}

La necesidad de contar con un albergue digno se reconoce tanto en la obligación constitucional del Estado de promover la construcción de viviendas populares, como en los objetivos de desarrollo planteados por MIDEPLAN con miras a la erradicación de los asentamientos en precarios y tugurios. Sin embargo, la evidencia no sólo confirma que persisten en el país grupos importantes de personas que no cuenta con una vivienda adecuada, sino también la correlación que existe entre esta carencia y la privación en otros indicadores sociales, lo que da cuenta de la vulnerabilidad y la desventaja social que sufren quienes viven en estas condiciones.

En este sentido, Mora (2014) señala la existencia de diferencias conceptuales importantes entre el tugurio y el asentamiento informal. El primero se refiere a una condición estructural de la vivienda, mientras que el segundo se relaciona con aspectos legales vinculados a la "toma ilegal de tierra" (Adamson et al., 2014: 367) sobre la que se construye la vivienda. Esto es un elemento de interés en la medida en que la aspiración de un albergue digno no se circunscribe únicamente y exclusivamente a aspecto ligados con los materiales de construcción o el estado físico de la vivienda, sino también por un elemento legal asociado a la propiedad de la tierra.

Por lo tanto, se incluyen en la medición una serie de indicadores que den cuenta de la existencia de privaciones vinculadas con el hacinamiento y la calidad de la vivienda. En el primer caso se iden-

\footnotetext{
${ }^{7}$ Según la ENAHO de 2013, un $99.72 \%$ de las viviendas costarricenses cuentan con luz eléctrica, un $94.60 \%$ utiliza fuentes de agua para consumo que provienen de acueductos, cooperativas o empresas regionales, y un $99.37 \%$ se abaste de agua en las viviendas por medio de tuberías. Estos porcentajes de cobertura, si bien varían entre la zona urbana y rural, dan cuenta de la necesidad de desarrollar indicadores que permitan medir no la cobertura, sino más bien la calidad del servicio prestado, siendo esta una limitación que también se identifica en países como Colombia o México, lo que apunta nuevamente a la necesidad de mejorar las fuentes de información disponibles.
} 
tifica que la persona (familia) sufre una carencia cuando se verifica que existen hogares (viviendas) con más de tres personas por dormitorio ${ }^{8}$. En el segundo caso, se identifica que una persona (familia) experimenta una privación cuando se verifica alguna de las siguientes situaciones: personas (familias) en vivienda eventual o tugurio; personas (familias) en viviendas con materiales de desecho $u$ otros en las paredes y techos, o piso de tierra; y personas (familias) en viviendas con materiales en mal estado de manera simultánea en paredes y techos, y pisos de tierra.

\section{Dimensión 2: servicios públicos domiciliarios}

Los servicios públicos domiciliarios son considerados en diversas legislaciones alrededor del mundo como un derecho colectivo de los ciudadanos en la medida en que constituyen un medio para el logro de un nivel de vida adecuado que contribuya con el desarrollo de las personas y las comunidades en general.

En este sentido, se incluye en la medición un indicador que dé cuenta de las fuentes de energía utilizadas para cocinar. Se identifica como pobre multidimensional a aquella persona (hogar) que utilice leña, carbón o desechos para cocinar, mismos que, para los efectos del presente ejercicio, son considerados como fuentes de energía inadecuadas.

Es importante señalar que según los parámetros establecidos por el INEC en la aplicación de la ENAHO, el término "desecho" incluye el uso de biodigestores para la generación de gas, por lo que si bien se considera que esta última es una fuente adecuada para cocinar, al no permitir la encuesta hacer algún tipo de distinción, se decidió finalmente considerar a la categoría en su conjunto como inadecuada para los efectos del presente ejercicio.

\section{Dimensión 3: tecnologías de la información y la comunicación (TIC)}

El acceso a una computadora o la Internet representa no sólo una oportunidad, sino también una necesidad en la llamada sociedad del conocimiento. En este sentido, Núñez (2014) citando a la Fundación Omar Dengo (2006), señala que el uso de tecnologías digitales contribuye con la equidad al "ofrecer condiciones y oportunidades concretas para el desarrollo de capacidades en las personas, relacionadas con el procesamiento de información,

\footnotetext{
${ }^{8}$ Según Pujol et al. (2014), este indicador podría dejar de ser relevante dentro de unos años en caso de mantenerse la tendencia a la reducción del número de miembros que conforman una familia en Costa Rica.
}

la creación de conocimiento, la resolución de problemas y la comunicación" (Adamson et al., 2014: 449), siendo esta un área definida como prioritaria por el MIDEPLAN de cara al cumplimiento de las metas de desarrollo de 2030.

Siguiendo las políticas del Ministerio de Educación Pública (MEP) se definió la población expuesta al uso de las computadoras o Internet como aquella que posea 5 años o más, identificando como pobres multidimensionales a aquellas personas (familias) en las que se verifiquen al menos dos de las siguientes situaciones: viviendas que no cuentan con una computadora portátil o de escritorio; viviendas que no cuentan con acceso a Internet; y residentes de la vivienda de 5 años o más que no han usado Internet en los últimos 3 meses.

\section{Dimensión 4: vida saludable}

En 2010 la Asamblea General de la Naciones Unidas reconoció, de manera explícita, el derecho humano al agua y al saneamiento. De igual forma, UNICEF (2007) señaló que el derecho a entornos saludables para la infancia y la adolescencia implica no sólo el acceso a servicios básicos de calidad, sino también a un ambiente que proteja la salud y estimule el desarrollo pleno de las capacidades, siendo en este sentido el "derecho a gozar de agua suficiente, segura y físicamente accesible, así como de servicios de saneamiento apropiados" (UNICEF, 2007: 4) elementos indispensables para alcanzar una vida digna y un desarrollo sostenible.

Por lo anterior, se incluye dentro de la medición una serie de indicadores que den cuenta de la existencia de carencia en el consumo de agua potable y el saneamiento básico, identificándose como pobre multidimensional a aquella persona (hogar) cuya fuente de consumo de agua sea considerada inadecuada (pozos, ríos o lluvia), o bien que cuente con un sistema inadecuado para la eliminación de las excretas (pozos, otros sistemas o no tiene algún sistema de eliminación).

\section{Dimensión 5: medio ambiente}

Adamson, Castillo y Varela (2014) señalan que "el impacto negativo de la falta de manejo sostenible de los desechos sólidos y líquidos, así como la falta de políticas claras dirigidas hacia los hogares, tales como el reciclaje, le impone al país un costo ambiental considerable" (Adamson et al., 2014: 432 ), siendo este un hecho que contrasta con la vocación ambientalista de que goza el país a nivel internacional. 
En línea con lo anterior, Gómez (2014) señala que dentro de las llamadas buenas prácticas ambientales se incluyen la disposición adecuada de las excretas, el uso de fuentes renovables de electricidad, o la disposición adecuada de la basura, siendo todos estos elementos en los que el país presenta deficiencias importantes.

A partir de lo expuesto con anterioridad, se incluye en la medición un indicador que dé cuenta de la adecuada disposición de la basura (sólida), identificando como pobre multidimensional a aquella persona (hogar) que queme, entierre, o lance la basura a tiraderos clandestinos, o a los márgenes de los ríos.

\section{Dimensión 6: educación básica}

La educación y la inversión en capital humano se reconocen hoy en día como herramientas fundamentales para el desarrollo socioeconómico de cualquier país. Sin embargo, la globalización y el cambio tecnológico trajeron consigo una revaloración de las competencias que requiere una persona para lograr una inserción favorable en el mercado laboral, concluyéndose finalmente que la educación primaria resulta insuficiente para tales fines.

Sobre este particular, Trejos y Sáenz (2014) señalan que completar la educación secundaria constituye hoy en día el capital humano mínimo necesario para dar igualdad de oportunidades a las personas y garantizar la competitividad del país, siendo relevante desde este punto de vista ya no sólo los aspectos vinculados a la cobertura (acceso), sino también a la asistencia, retención, logro (resultados) y calidad de la educación, entre otros.

Por lo tanto, se incluyen en la medición una serie de indicadores que permitan identificar la existencia de privaciones en lo que respecta a la asistencia, el rezago, y el logro educativo en la educación básica formal (preescolar, primaria y secundaria).

En lo que respecta a la asistencia y el rezago escolar, se definió un rango etario de entre 7 y 17 años, mientras que para el logro educativo se estableció una edad superior a los 24 años. En este sentido, se considera que un persona (hogar) experimenta una privación cuando se verifica que: existen jóvenes de 7 a 17 años que no asisten a la educación formal; existen jóvenes de 7 a 17 años que asiste a la educación regular con un rezago mayor a dos años; y existen personas mayores de 24 años que no han completado la educación secundaria (académica o técnica).

\section{Dimensión 7: exclusión social}

Según Mazzei (2014) la población joven que ni estudia, ni trabaja, conocida como "ni-ni", no sólo constituye un grupo doblemente excluido, sino que involucra a personas en edades claves para el desarrollo del país, pudiendo identificarse entre sus miembros cuatro subgrupos específicos: desempleados, mujeres con responsabilidades, jóvenes que asisten a educación no regular, y un núcleo duro que no presenta alguna característica en particular, lo que da cuenta no sólo de la heterogeneidad de sus integrantes, sino también de una serie de particularidades que "propician la pertenencia a la condición «ni-ni» y obstaculizan su salida" (Adamson et al., 2014: 173).

Así las cosas, se incluye un indicador que dé cuenta de la exclusión social, definiéndose para tales efectos un rango etario de entre 12 y 24 años, identificando como pobres multidimensionales a aquellos jóvenes que no asisten a la educación formal ni cuentan con un empleo remunerado.

Es importante señalar que en la práctica el análisis de los "ni-ni" se realiza a través de dos segmentos claramente diferenciables por la dinámica social asociada a sus miembros, por lo que los resultados de las mediciones se presentan para los subgrupos comprendidos entre los 12 y 17, y los 18 y 24 años, siendo este último subgrupo el que experimenta las peores condiciones en la medida en que al no tener acceso al conocimiento le es imposible generar un ingreso digno al llegar a la edad adulta.

\section{Dimensión 8: calidad del empleo}

Según Menéses y Gutiérrez (2014), la estructura laboral predominante en los años 1980, caracterizada por la agricultura y la industria tradicional, ha sido sustituida por otra en la que los servicios empresariales y financieros, el turismo, la agroexportación y las zonas francas adquieren cada vez una mayor relevancia. Esta situación si bien se traduce en una serie de oportunidades para los trabajadores mejor calificados, se convierte en una desventaja para aquellos que continúan vinculados con actividades tradicionales, generando con ello una marcada diferencia en materia de productividad la cual traduce a su vez en desigualdades importantes en el mercado laboral.

Por lo anterior, se incluye dentro de la medición una serie de indicadores que den cuenta de las privaciones existentes en materia de subempleo, insatisfacción laboral y estabilidad en el empleo, siendo todas estas verificadas en aquellas personas identificadas como ocupadas en la ENAHO. Se identifi- 
ca como pobre multidimensional a aquella persona ocupada que presenta al menos dos de las siguientes situaciones: trabaja menos de 40 horas semanales; no se encuentran satisfechos en su empleo actual; y no cuentan con un empleo permanente.

\section{Dimensión 9: seguridad social}

Según la consulta efectuada por MIDEPLAN, dentro de las metas prioritarias de desarrollo identificadas por los costarricenses se incluye la universalización de la cobertura de los sistemas de seguridad social y de pensiones, siendo en este sentido el segmento de los adultos mayores uno de los más sensibles como consecuencia del envejecimiento de la población.

Es por esto que se incluyen dentro de la medición una serie de indicadores que permitan dar cuenta de la existencia de privaciones en lo que respecta a la afiliación al seguro social y a un régimen básico de pensiones, identificando como pobre multidimensional a aquella persona ocupada que no cuente con seguro social y que, siendo asalariada -incluso por cuenta propia- no cotice para un régimen básico de pensiones.

Por su parte, en el segmento de adulto mayor, se identifica como pobre multidimensional a aquella persona que estando fuera de la fuerza laboral no cuente con seguro social, o bien no se encuentre pensionado por algún régimen de pensiones contenido en la ENAHO.

Es importante mencionar que a raíz de las modificaciones introducidas en el Sistema Nacional de Pensiones (Ley de Protección del Trabajador, 2000), en la actualidad se cuenta con un sistema de pensiones de múltiples pilares de protección, conformado por el régimen básico de pensiones obligatorio, el régimen complementario obligatorio, el régimen complementario voluntario, y el régimen no contributivo, por lo que resulta de interés, para efectos de mejorar los indicadores de medición, incluir dentro de la ENAHO información que dé cuenta de la afiliación a los distintos regímenes de pensiones existentes en la actualidad, por lo que este indicador en particular deberá ser objeto de revisión en el corto plazo.

\section{Elección del valor k (línea de corte en- tre dimensiones)}

En lo que respecta a la elección de la línea de corte entre dimensiones (el parámetro $\mathrm{k}$ del modelo de Alkire y Foster), es importante recordar que al día de hoy no existe consenso en relación al número de privaciones a partir de las cuales una persona (hogar) debe considerarse pobre en términos multidimensionales. En la práctica este umbral es definido a través de diversos criterios estadísticos o bien de la observación del número de privaciones que experimentan los diferentes grupos de la población. $\mathrm{Al}$ ser este un ejercicio exploratorio se estimó la incidencia de la pobreza para distintos valores de $\mathrm{k}$ siendo los resultados finales presentados en función de un valor $\mathrm{k}=3$.

Un resumen de las dimensiones, privaciones, indicadores y pesos relativos utilizados en el ejercicio exploratorio de medición multidimensional de la pobreza se presenta en la Tabla 1.

\section{Análisis de resultados}

A partir de la información disponible en la ENAHO (2010 a 2013) se estimó la incidencia de la pobreza multidimensional según las dimensiones (9), privaciones (18) e indicadores (21) propuestos, de manera exploratoria, para la construcción del índice sintético de pobreza multidimensional. En todos los casos se utilizó a la persona como unidad de análisis, considerándose el hogar (vivienda) en aquellos casos en los que no fue posible establecer una medida a nivel individual.

En el cálculo de la incidencia de la pobreza se utilizaron distintos valores del parámetro k (línea de corte entre dimensiones), observándose que la identificación de personas en situación de pobreza multidimensional aumenta a medida que de dicho parámetro es menor. En términos teóricos esto equivale desplazarse desde un método de identificación más inclusivo (método de la unión, $\mathrm{k}=1$ ) a uno más restrictivo (método de la intersección, $\mathrm{k}=4$ o superior), lo que podría generar estimaciones exageradas (error de inclusión) o bien restringidas (error de exclusión) del nivel de pobreza.

Por lo anterior, si bien no existe un método determinístico para el cálculo del parámetro k, en la práctica suele utilizarse un valor $\mathrm{k}=33 \%$ lo que implica en este caso que la persona es identificada como pobre multidimensional cuando la cantidad de dimensiones en las que sufre privaciones es por lo menos tres dimensiones.

Al utilizar un valor de $\mathrm{k}=3$ se observó que las dimensiones que más aportan al índice sintético son las vinculadas a las tecnologías de la información y la comunicación (TIC), la educación básica, y la calidad del empleo. Por su parte, las que en apariencia aportaron menos al indicador son las vinculadas a la vida saludable y los servicios públicos domicilia- 
Tabla 1: Índice de pobreza multidimensional (exploratorio)

\begin{tabular}{|c|c|c|c|c|}
\hline \multicolumn{2}{|c|}{ DIMENSIONN } & \multicolumn{3}{|r|}{ CARENCIAS } \\
\hline & Peso (\%) & Privación & Peso (\%) & Indicador \\
\hline \multirow[t]{2}{*}{ Albergue digno } & 0,111 & Calidad de vivienda & 0,056 & $\begin{array}{l}\text { Se verfica al menos una de las siguientes stuaciones: } \\
\text { i) Vivienda eventual o tugurio (incluye cuarterias) } \\
\text { i) Vivienda de paredes de desecho u otro o techo de desecho o piso de terra. } \\
\text { i) Vivienda con materiales en mal estado simultaneamente en paredes, techo y piso. }\end{array}$ \\
\hline & & Hacinamiento & 0,056 & i) Viviendas con más de tres personas por dormitorio. \\
\hline $\begin{array}{l}\text { Servicios públicos } \\
\text { domiciliarios }\end{array}$ & 0,111 & $\begin{array}{l}\text { Fuente de energia } \\
\text { usada para cocinar }\end{array}$ & 0,111 & i) Viviendas que utilizan fuentes inadecuadas de energia para cocinar (lefia o carbón, u otros desechos) \\
\hline \multirow{3}{*}{$\begin{array}{l}\text { Tecnologias de la } \\
\text { información y la } \\
\text { comunicación }\end{array}$} & 0,111 & Tenencia & 0,037 & $\begin{array}{l}\text { Se verfican al menos una de las siguientes situaciones: } \\
\text { i) Viviendas que no cuentan con una computadora (portatil o de escrtorio) }\end{array}$ \\
\hline & & Acceso & 0,037 & i) Viviendas que no cuentan con acceso a internet \\
\hline & & Uso & 0,037 & ii) Residentes de la vivienda de 5 ahos o más que no han usado imternet en los útimos 3 meses \\
\hline \multirow[t]{2}{*}{ Vida saludable } & 0,111 & $\begin{array}{l}\text { Consumo de agua } \\
\text { potable }\end{array}$ & 0,056 & i) Vivienda que consume agua de fuente inadecuada (pozo, rio o lluvia). \\
\hline & & Saneamiento básico & 0,056 & i) Vivienda con inadecuado sistema de eliminación de excretas (pozo, otro sistema o no tiene). \\
\hline Medio Ambiente & 0,111 & $\begin{array}{l}\text { Disposición de la } \\
\text { basura }\end{array}$ & 0,111 & i) Viviendas que no cuentan con mecanismos apropiados para la eliminación de la basura (queman, entierran, traderos, rios). \\
\hline \multirow[t]{3}{*}{ Educación básica } & 0,111 & Asistencia & 0,037 & $\begin{array}{l}\text { Se verfican al menos una de las siguientes stuaciones: } \\
\text { i) Jovenes de } 7 \text { a } 17 \text { aflos que no asisten a la educación formal. }\end{array}$ \\
\hline & & Rezago & 0,037 & i) Jovenes de 7 a 17 atos que asiste a la educación regular con rezago mayor a dos aflos \\
\hline & & Logro educativo & 0,037 & i) Personas mayores de 24 afos que no hayan completado la educación secundaria (académica o técrica). \\
\hline Exelusión social & 0,111 & $\begin{array}{l}\text { Jovenes que no } \\
\text { estudian ni trabajan }\end{array}$ & 0,111 & i) Jovenes de 12 a 24 años que no asiste a la educación formal ni tiene trabajo remunerado \\
\hline \multirow[t]{2}{*}{ Calidad del empleo } & 0,111 & Subempleo & 0,037 & $\begin{array}{l}\text { Se verfica al menos una de las siguientes stuaciones en las personas ocupadas: } \\
\text { i) Trabajadores que laboran menos de } 40 \text { horas semanales. }\end{array}$ \\
\hline & & Insatistacción laboral & 0,037 & i) Trabajadores que no se encuentran satisfechos en su empleo (ocupación) actual. \\
\hline \multirow{3}{*}{ Seguridad Social } & & $\begin{array}{l}\text { Estabilidad del } \\
\text { empieo }\end{array}$ & 0,037 & i) Trabajadores que no cuentan con un empleo permanente. \\
\hline & 0,111 & Seguro Social & 0,056 & $\begin{array}{l}\text { Se verfica alguna de las siguientes situaciones: } \\
\text { i) Personas ocupadas que no cuenten con seguro social. } \\
\text { i) Personas de } 65 \text { affos o más, que estén fuera de la fuerza de trabajo, que no cuente con seguro social (pensión) }\end{array}$ \\
\hline & & $\begin{array}{l}\text { Sistema de } \\
\text { pensiones }\end{array}$ & 0,056 & i) Personas que se encuentren trabajando (asalariado, convenio o cuenta propia) que no cotizan al régimen básico de pensiones. \\
\hline
\end{tabular}

Fuente: Elaboración propia

rios.

Es importante señalar que si bien una dimensión puede en el agregado reflejar un aporte relativamente pequeño, detrás del número puede ocultarse la existencia de asimetrías importantes en circunstancias que configuran una situación de pobreza. En este sentido, se desagregó el resultado de las dimensiones asociadas a la vida saludable y el medio ambiente en función de las zonas y regiones de planificación en que se divide el país, identificando la existencia de disparidades considerables entre la zona urbana y la zona rural, así como entre la región central y las regiones costeras o fronterizas.

En este sentido, en lo que respecta al consumo de agua potable, asociada a la dimensión calidad de vida, para el 2013 se identificó que un $5.4 \%$ de las personas acceden a fuentes de consumo inadecuados. Sin embargo, este porcentaje aumenta a un $16.7 \%$ en la zona rural, siendo este un hecho que se repite al desagregar el resultado por región de planificación identificándose carencias de hasta un $18.3 \%$ en la zona Huetar atlántica, en comparación con el $1.4 \%$ identificado en la zona central del país.

Por su parte, en lo que respecta a la disposición adecuada de los desechos sólidos, asociada a la dimensión del medio ambiente, en el 2013 se identificó que un $11.5 \%$ de personas sufren privaciones en esta área, siendo esta cifra del $39.7 \%$ en la zona rural, y del $34.2 \%$ en región Brunca, esto último en contraposición con el $2.1 \%$ de la región central.

En la dimensión vinculada con el albergue digno se identificó en el 2013 que alrededor del $7 \%$ de las personas sufren privaciones en lo que respecta a la calidad de la v ivienda (tugurios, materiales de construcción, y conservación). Por su parte, un $4 \%$ sufre privaciones desde el punto de vista del hacinamiento (más de tres personas por dormitorio). En lo que respecta a la fuente de energía para cocinar, asociada a la dimensión de servicios públicos domiciliarios, en el 2013 se identificó que un $6 \%$ de las personas utilizan fuentes inadecuadas (carbón, leña o desechos).

La dimensión asociada a las tecnologías de la información es una de las que más aporta al resultado final del índice sintético, identificando en el 2013 que un $44.6 \%, 49.3 \%$ y $23.2 \%$ de las personas sufren privaciones en la tenencia, uso y acceso a las TIC respectivamente. 
Por su parte, en la dimensión asociada a la educación básica, se identificó que en el 2013 el $60.9 \%$ de las personas mayores de 24 años no cuenta con secundaria completa (logro educativo), mientras que un $6.2 \%$ y $12.8 \%$ respectivamente de los jóvenes entre 7 y 17 años presentan carencias en lo que respecta a la asistencia y el rezago escolar.

La exclusión social, medida a través del grupo de jóvenes entre 12 y 24 años que no asisten a la educación formal ni cuenta con un trabajo remunerado (ni-ni) identificó en el 2013 como carentes a un $15.7 \%$ de las personas ubicadas dicho rango de edad. Este resultado disminuye a un $8 \%$ para las personas entre 12 y 17 años, y aumenta a un $21.8 \%$ para las ubicadas entre 18 y 24 años.

En lo que respecta a la calidad del empleo, en el 2013 se identificó que en el grupo de las personas ocupadas, un $14.1 \%$ sufre privaciones por subempleo (labora menos de 40 horas semanales), un $21.8 \%$ por insatisfacción laboral, y un $9.5 \%$ por estabilidad laboral (no cuenta con empleo de largo plazo), siendo esta la tercer dimensión en importancia en lo que respecta al aporte total al índice sintético.

Finalmente, en la dimensión asociada a la seguridad social se identificó en el 2013 como privados desde el punto del acceso al seguro social (salud) al $12.4 \%$ de las personas ocupadas, mientras que en el grupo de las personas que se encuentran trabajando (asalariados, convenio o cuenta propia) se identificó que un $1.3 \%$ no cotiza a algún régimen básico de pensiones.

En términos generales, y según los distintos valores asignados al parámetro $\mathrm{k}$, el porcentaje de personas identificadas en situación de pobreza multidimensional ha venido disminuyendo desde el 2010 y hasta la fecha, siendo para el 2013 de un $31.5 \%$ si se toma como referencia $\mathrm{k}=3$.

*Conclusiones y recomendaciones

La medición de la pobreza a partir de parámetros que no estén vinculados con indicadores monetarios surge a partir del reconociendo de que este es un fenómeno multidimensional que no puede ser medido con un único indicador. Las mediciones multidimensionales de la pobreza son en este sentido herramientas de desarrollo humano que permiten alinear las políticas públicas destinadas a la superación de este fenómeno.

Son varios los retos que presenta la adopción de una medida multidimensional de la pobreza. Desde el punto de vista metodológico los más relevantes se vinculan con la selección de la unidad de análisis; la definición de las dimensiones, carencias e indica- dores que conforman el índice sintético; la importancia relativa que se le asigna a cada dimensión y carencia; y la definición de los puntos de corte, tanto a lo interno como entre las dimensiones. Alrededor de estos elementos, si bien existe un soporte conceptual adecuado, no existe un consenso metodológico, lo que abre un espacio a la subjetividad, misma que se evidencia al momento de asignarle la misma importancia relativa a las dimensiones, o bien al darle un mayor peso a determinado indicador en detrimento de otro. El hecho de que exista esta subjetividad en la toma de decisiones por parte del investigador o del hacedor de políticas no puede ser visto per se como algo negativo, siendo más bien necesario explicitar las decisiones y contar con los argumentos necesarios para defender la alternativa metodológica adoptada.

Desde el punto de vista institucional es indispensable que la medición sea desarrollada y aplicada por un organismo técnico competente, siendo en este sentido el INEC la institución encargada de garantizar no sólo la solidez e independencia de la medición, sino también el desarrollo de mecanismos que permitan modificar los parámetros sobre los se estructura.

En términos políticos, los mayores retos se relacionan con el seguimiento que se le brinde a la medición, la estrategia comunicacional que se siga para darla a conocer a los ciudadanos, y la rendición de cuentas a partir de los resultados obtenidos al calcular la incidencia de la pobreza multidimensional. En el primero de los casos las experiencias más exitosas a nivel internacional dan cuenta de la conveniencia de constituir una mesa permanente de trabajo que monitoree y coordine los esfuerzos en materia de desarrollo humano, siendo esto de gran utilidad para garantizar la incidencia directa de las políticas públicas en aquellas áreas que registran un número considerable de carencias.

La estrategia comunicacional no sólo debe servir como apoyo a las políticas públicas que promueve el Estado, sino también como un medio para que los ciudadanos conozcan y entiendan lo que se busca al adoptar una medida de esta naturaleza.

Finalmente, un aspecto relevante al adoptar una medida multidimensional es la posibilidad de rendir cuentas sobre las acciones de política pública destinadas a la superación de la pobreza. El índice sintético es, en este sentido, una herramienta que permite identificar aquellas dimensiones y variables que experimentan el mayor porcentaje de rezago. Esto debiera dar indicios de la existencia de fallas en el diseño o la ejecución de las políticas.

Proyectar un índice de pobreza multidimensio- 
nal a partir de las metas sectoriales establecidas en el plan nacional de desarrollo o en los documentos elaborados por el MIDEPLAN, no sólo legitima la toma de decisiones, sino que garantiza el cumplimiento de las políticas en la medida en que se logre asociar los indicadores del índice con las metas sectoriales del plan.

En este sentido, es importante señalar la alta sensibilidad de los resultados a distintos valores del parámetro k (línea de corte entre dimensiones), lo que implicó transitar de una incidencia de la pobreza multidimensional del $79 \%(\mathrm{k}=1)$ a una del $18 \%$ $(\mathrm{k}=4)$, evidenciando con ello las posibles implicaciones políticas de adoptar un punto de corte más o menos riguroso. En la práctica este punto suele definirse a través de diversos métodos estadísticos, siendo $\mathrm{k}=3$ el parámetro más utilizado, lo que representa, en este caso en particular, una incidencia de la pobreza multidimensional del $31.5 \%$.

Para el año 2013, tomando un valor de $\mathrm{k}=3$, se observa que las dimensiones asociadas a las tecnologías de la información y las comunicaciones (28\%), educación básica (25\%), y en menor medida la calidad del empleo (16\%) son las que más aportan al resultado general del índice sintético, siendo estos porcentajes en términos comparativos muchos más altos que los observados en las dimensiones asociadas a los servicios públicos domiciliarios $(3 \%)$ y vida saludable (3\%) las cuales aportan los resultados más bajos del índice.

La existencia de brechas tan amplias entre las dimensiones llama a la reflexión en la medida en que las mismas han sido definidas como "de interés" para la sociedad costarricense, evidenciando con ello que lo hecho hasta la fecha ha sido insuficiente para procurar un mayor nivel de bienestar a la población.

En este sentido, que un $44.6 \%$ de las personas no cuente con una computadora o que el $49.3 \%$ no acceda a la Internet, son hechos que contrastan de manera importante con las metas de desarrollo establecidas por el MIDEPLAN de cara al 2030 acceso universal a Internet, $100 \%$ de uso de las TIC en el proceso de aprendizaje, y $100 \%$ de conexión a Internet de banda ancha-. De la misma forma, que un $60.9 \%$ de las personas mayores de 24 años no haya completado la educación secundaria evidencia fallas importantes en lo que respecta al logro educativo (secundaria completa) y la tasa de escolaridad.

En los resultados del ejercicio se observa un agotamiento importante de los indicadores incluidos en la dimensión "calidad de la vivienda", como el tipo de vivienda y la construcción con materiales de desecho o pisos de tierra, y en menor medida de las viviendas con materiales en mal estado y condicio- nes de hacinamiento. Esto plantea la necesidad de redefinir dichos indicadores en función de nuevos elementos que puedan ser percibidos como configuradores de una situación de pobreza. Algunos indicadores alternativos podrían dar cuenta del acceso a zonas verdes y de esparcimiento, o la calidad de los caminos, por citar algunos ejemplos, sin embargo, esta no es información que esté disponible, por lo que se plantea la necesidad de mejorar las fuentes de información a fin de garantizar la pertinencia de los resultados obtenidos.

Una medición multidimensional, al permitir la desagregación de los resultados en función de los indicadores propuestos, permite analizar la composición de la pobreza, orientando la toma de decisiones y modificando las políticas públicas en aquellas dimensiones que registren el mayor porcentaje de carencias. Los resultados también pueden ser expresados en función de la zona o región de planificación, lo que permitiría una focalización geográfica de las políticas en aquellas que presenten las mayores brechas.

En línea con lo anterior, al desagregar los resultados de las dimensiones asociadas al medio ambiente y la vida saludable se evidencia la existencia de asimetrías importantes entre las zonas y regiones de planificación. Esto confirma la importancia de mirar más allá del resultado agregado en la medida en que este puede ocultar información relevante.

En la práctica la selección de las dimensiones e indicadores se ve limitada por las fuentes de información existentes, siendo este uno de los mayores retos a los que se enfrenta el INEC en su calidad de órgano rector de la actividad estadística del país, la mejora de las fuentes de información disponibles de forma tal que sea posible incorporar nuevos y mejores indicadores en el índice sintético, así como la realización de estudios complementarios que permitan ampliar los datos y, a partir de ellos, mejorar la toma de decisiones destinada a la superación de la pobreza. Todo esto siempre bajo la premisa de que las dimensiones y los indicadores deben ser susceptibles de ser impactadas por medio de las acciones de las políticas públicas.

El mejoramiento de las fuentes de información, si bien es indispensable para garantizar la pertinencia de las mediciones, plantea preguntas importantes en la medida en que se requiere por un lado garantizar la continuidad y el diseño metodológico de las encuestas utilizadas, y por otro contar con fuentes de información que sean actualizables en el tiempo, lo que garantizaría la pertinencia de los indicadores planteados, siendo esta disyuntiva resuelta en la práctica a través de la confección de un módulo especial en la encuesta de hogares. 
En el caso particular de Costa Rica, este módulo podría incluir datos sobre la calidad de los servicios públicos domiciliarios, la calidad de los servicios de salud, la calidad de la educación, la cotización a fondos complementarios de pensiones (obligatorios y voluntarios), el acceso a zonas verdes y de esparcimiento, la calidad de los caminos, y algunos aspectos nutricionales.

En lo que respecta a los estudios complementarios, se considera fundamental la realización de encuestas longitudinales (tipo panel) que permitan observar la evolución de los hogares en situación de pobreza a través del seguimiento continuo de los mismos, así como la realización de estudios actualizados sobre la percepción de la pobreza en aquellas personas que viven en esta situación. Esto permitiría identificar dimensiones prioritarias y establecer si las políticas públicas están en sintonía con lo que los ciudadanos perciben.

A partir de la experiencia de otros países, se considera oportuno instalar una discusión sobre la conveniencia de contar o no con un panel de expertos en temas vinculados a la medición multidimensional de la pobreza, que proponga actualizaciones que permitan garantizar la vigencia de los indicadores, así como transparencia y comprensión de la medición por parte del ciudadano.

Si bien es necesario reconocer que las mediciones de la pobreza basadas en indicadores monetarios brindan una mira parcial de un fenómeno que es multidimensional, no puede desconocerse la importancia del ingreso como medio para mejorar las condiciones de vida de las personas, por lo que su uso en una medida multidimensional de la pobreza permitiría llenar algunos vacíos de información que puedan existir al momento de identificar a las personas en situación de pobreza multidimensional. En este sentido, las mediciones multidimensionales desarrolladas por CONEVAL y CEPAL, en las que se incluye un indicador monetario, han demostrado ser más acertadas en la identificación de las pobres multidimensionales.

Se deben incluir aspectos que den cuenta de la vulnerabilidad que experimentan las personas de los segmentos que se ubican más cerca de la línea de pobreza, a partir de la evidencia dada a conocer por el PEN (2013 y 2014) en relación a la movilidad descendente que experimentan el grupo de personas no pobres.

\section{Referencias}

Adamson, M., Castillo, F., y Varela, L. (2014). Hogares verdes en Costa Rica: Indicadores de prácticas de consumo sostenible. En Costa Rica a la luz del Censo 2011. Instituto Nacional de Estadística y Censos (INEC). San José, Costa Rica.

Alkire, S. (2007). Choosing dimensions: the capability approach and multidimensional poverty. Working Paper. Oxford Poverty y Human Development Initiative. Oxford, Inglaterra. Consultado el, 88.

Alkire, S. y Foster, J. (2007). Recuento y medición multidimensional de la pobreza. Documento de Trabajo. Oxford Poverty y Human Development Initiative, 7.

Angulo, R., Díaz, Y., y Pardo, R. (2011). Índice de pobreza multidimensional para colombia (ipmcolombia) 1997-2010. Documento 382. Archivos de Economía. Dirección de Estudios Económicos.

Arrow, K. (1951). Social choice and individual values. Yale University.

Bentham, J. (2014). An introduction to the principles of morals and legislation. oxford, inglaterra.

Bustamante, J. (2013). Índice de pobreza multidimensional (IPM) Colombia. CEA-CEPAL. Pucón, Chile.

CEPAL (2013). Panorama social de América Latina.

CLACSO (2009). Pobreza. Un glosario internacional. CLACSO.

Comisión Presidencial para la Medición de la Pobreza (2014). Informe Final. . Santiago, Chile.

CONEVAL (2011). Metodología para la medición multidimensional de la pobreza en México.

CONPES (2012). Metodologías oficiales y arreglos institucionales para la medición de la pobreza en Colombia.

de la Nación, P. E. (2014). Vigésimo Informe Estado de la Nación en Desarrollo Humano Sostenible. San José, Costa Rica.

Denis, A., Gallegos, F., y Sanhueza, C. (2010). Medición de la pobreza multidimensional en Chile. Universidad Alberto Hurtado. Santiago de Chile.

Feres, J. (2014). Curso sobre Pobreza y distribución del ingreso.

Feres, J. y Mancero, X. (2001a). El método de las necesidades básicas insatisfechas (NBI) y sus aplicaciones en América Latina. Serie Estudios estadísticos y prospectivos. CEPAL, Santiago de Chile. 
Feres, J. y Mancero, X. (2001b). Enfoques para la medición de la pobreza. Breve descripción de la literatura. Serie Estudios estadísticos y prospectivos, CEPAL, Santiago de Chile.

Fundación para la Superación de la Pobreza (2010). Voces de la pobreza. Significados, representaciones y sentir de personas en situación de pobreza a lo largo de Chile.

Fundación para la Superación de la Pobreza (2014). Mediciones de pobreza alternativas para el caso de Chile. Documento de trabajo Área de Propuestas País. Santiago de Chile.

Gómez, A. (2014). Estimación del índice de Sostenibilidad Cantonal con información censal. En Costa Rica a la luz del Censo 2011.

Hernández, R., Fernández, C., y Baptista, P. (2010). Metodología de la Investigación. McGraw-Hill, México D.F.

Kaldor, N. (1939). Welfare propositions of economics and interpersonal comparisons of utility, volumen 49.

Kaztman, R. y Gerstenfeld, P. (1988). La heterogeneidad de la pobreza: Una aproximación bidimensional. CEPAL, Montevideo.

Mazzei, A. (2014). aracterización de la población "nini": ni estudia, ni trabaja. En Costa Rica a la luz del Censo 2011.

Méndez, F. y Bravo, O. (2014). Costa rica. mapas de pobreza 2011. En Costa Rica a la luz del Censo 2011.

Menéses, K. y Gutiérrez, M. (2014). Tipos de economía, heterogeneidad productiva y ocupación en los censos 2000 y 2011. En Costa Rica a la luz del Censo 2011.

MIDEPLAN (2012). Proyecto Bicentenario: objetivos, metas e indicadores de desarrollo para la Costa Rica del 2021.

MIDEPLAN (2013). Costa Rica 2030. Objetivos de desarrollo nacional.

Mora, S. (2014). Hogares en asentamientos informales: ¿Quiénes son? y ¿cómo viven? En Costa Rica a la luz del Censo 2011.

Mundial, B. (2000). La voz de los pobres. ¿hay alguien que nos escuche?. washington, d.c. estados unidos.
Núñez, O. (2014). Desigualdad en las oportunidades de acceso y uso de tecnologías digitales en la población costarricense, según el censo 2011. En Costa Rica a la luz del Censo 2011.

ONS Office for National Statistics (2014). Measuring what matters.

Pareto, V. (1909). Manual of political economy.

Pigou, A. (1920). The economics of welfare. Londres, Inglaterra.

PNUD (2013). Informe sobre Desarrollo Humano 2013. El ascenso del Sur: Progreso humano en un mundo diverso. Nueva York, Estados Unidos.

Pujol, R., Pérez, E., y Sánchez, L. (2014). Informalidad en la vivienda de la gran área metropolitana: El impacto de los proyectos de vivienda social, 2000-2011. En Costa Rica a la luz del Censo 2011.

Rawls, J. (2006). Teoría de la justicia. Fondo de Cultura Económica, México D.F.

Sanhueza, C. (2012). Cómo mejorar la medición de la pobreza en Chile.

SEDESOL (2013). Lineamientos para la identificación de personas u hogares en situación de pobreza.

Sen, A. (1976). Poverty: an ordinal approach to measurement, volumen 44 .

Sen, A. (2000). Desarrollo y libertad. Planeta, Barcelona.

Sen, A. (2010). La idea de la justicia. Taurus.

Spicker, P., Alvarez, S., y Gordon, D. (2009). Pobreza: un glosario internacional. Consejo Latinoamericano de Ciencias Sociales (CLACSOCROP), Buenos Aires.

The New Economics Foundation (2012). The happy planet Index: 2012 Report. A global index of sustainable well-being.

Trejos, J. y Sáenz, M. (2014). Brechas distritales en la formación de capital humano básico. 2000 - 2011.

Villatoro, P. (2012). La medición del bienestar a través de indicadores subjetivos: una revisión. Serie Estudios estadísticos y prospectivos. CEPAL, Santiago de Chile. 